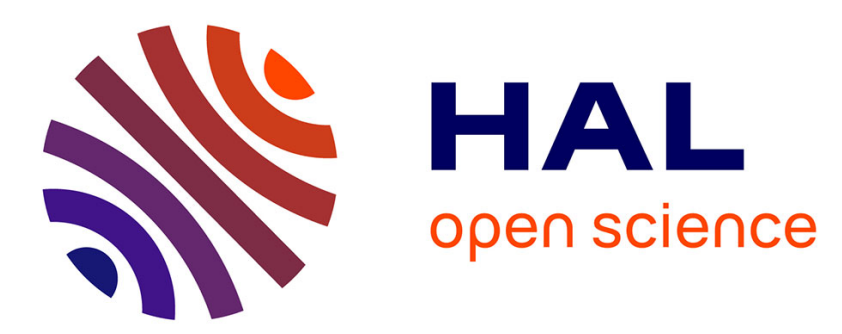

\title{
A new methodology for measurement of sludge residence time distribution in a paddle dryer using X-ray fluorescence analysis
}

Christophe Charlou, Mathieu Milhé, Martial Sauceau, Patricia Arlabosse

\section{- To cite this version:}

Christophe Charlou, Mathieu Milhé, Martial Sauceau, Patricia Arlabosse. A new methodology for measurement of sludge residence time distribution in a paddle dryer using X-ray fluorescence analysis. Water Research, 2015, 69, pp.1-8. 10.1016/j.watres.2014.11.005 . hal-01164610

\section{HAL Id: hal-01164610 https://imt-mines-albi.hal.science/hal-01164610}

Submitted on 17 Jun 2015

HAL is a multi-disciplinary open access archive for the deposit and dissemination of scientific research documents, whether they are published or not. The documents may come from teaching and research institutions in France or abroad, or from public or private research centers.
L'archive ouverte pluridisciplinaire HAL, est destinée au dépôt et à la diffusion de documents scientifiques de niveau recherche, publiés ou non, émanant des établissements d'enseignement et de recherche français ou étrangers, des laboratoires publics ou privés. 


\title{
A new methodology for measurement of sludge residence time distribution in a paddle dryer using $X$-ray fluorescence analysis
}

\author{
Christophe Charlou, Mathieu Milhé, Martial Sauceau, Patricia Arlabosse \\ Université de Toulouse; Mines Albi; CNRS ; Centre RAPSODEE, Campus Jarlard, 81013 \\ Albi, France
}

\begin{abstract}
:
Drying is a necessary step before sewage sludge energetic valorization. Paddle dryers allow working with such a complex material. However, little is known about sludge flow in this kind of processes. This study intends to set up an original methodology for sludge residence time distribution (RTD) measurement in a continuous paddle dryer, based on the detection of mineral tracers by X-ray fluorescence. This accurate analytical technique offers a linear response to tracer concentration in dry sludge; the protocol leads to a good repeatability of RTD measurements. Its equivalence to RTD measurement by $\mathrm{NaCl}$ conductivity in sludge leachates is assessed. Moreover, it is shown that tracer solubility has no influence on RTD: liquid and solid phases have the same flow pattern. The application of this technique on sludge with different storage duration at $4{ }^{\circ} \mathrm{C}$ emphasizes the influence of this parameter on sludge RTD, and thus on paddle dryer performances: the mean residence time in a paddle dryer is almost doubled between 24 and $48 \mathrm{~h}$ of storage for identical operating conditions.
\end{abstract}

Keywords: Sewage sludge; Residence time distribution; Paddle dryer; X-ray fluorescence

\section{Introduction}

Sewage sludge (SS) is the main by-product from wastewater treatment plants (WWTP): this mixture is globally nitrogen- and sulfur-containing organic material, microorganisms and minerals (mainly $\mathrm{P}, \mathrm{K}, \mathrm{Fe}, \mathrm{Ca}$, but also trace elements). SS is treated according to several pathways for stabilization of the biological activity (anaerobic or prolonged aerobic digestion for example), and/or dewatering (centrifuges, belt filters). In large-scale WWTPs, continuous dewatering equipment allow increasing the dry solid (DS) content of SS up to 20-30\% wt. (Chen et al., 2002). The traditional ways of disposal for this dewatered sludge are landfilling, agricultural reuse or incineration. While they still represent the major solutions in most countries, some have decided to limit or even prohibit agricultural reuse, considering SS as a waste due to heavy metal contents. In the mid-2000s, EU produced around 10Mt of dry sludge (Fytili and Zabaniotou, 2008), but due to legislation evolutions and population growth resulting in an increasing number of WWTP, the amount of SS produced will increase globally, so other ways of valorization of this carbonaceous material are worth investigating (Gendebien, 2010).

Whatever the outcome, SS requires a drying step after its dewatering for several reasons. Increasing the DS content in sludge leads to an increase in its calorific value, which is necessary in order to make energetic valorization such as co-incineration or gasification feasible (Arlabosse et al., 2011; Ferrasse et al., 2003; Manara and Zabaniotou, 2012; Mininni 
et al., 1997). Moreover, storage is unavoidable when one considers agricultural usage, since amendment cannot be realized anytime: this implies that the product is dry enough to be stable and easy to handle and store. The main challenge in SS drying and processing is the existence of a sticky state of the sludge while it is dried: it behaves as an elastic lump when reaching around $40 \%$ of dry solid (DS) content up until the point where granulation occurs and SS is free flowing (Kudra, 2003). This can be particularly problematic for processes where sludge is put in motion during drying because of sticking or clogging issues, resulting in mechanical damage in the installation. Moreover, when this pseudo-solid forms, it has a tendency to agglomeration that reduces the gas-to-solid or the heated-walls contact area. This sticky state results in both an increase in mechanical power needed for stirring as well as a decrease in the drying rate. Among the different industrial designs, paddle dryers appear as the most interesting: compact installations, low exhaust volumes and the ability to overcome efficiently the sticky phase make them very suitable for SS drying (Arlabosse et al., 2011). However, their design and operation remain largely empirical, and in most of the existing installations, SS reaches a DS content of about $95 \%$ at the outlet of the dryer, which is more than necessary for the possible energetic applications (specific incineration, co-incineration, pyrolysis, gasification). Drying is very energy-consuming, around $900 \mathrm{kWh} / \mathrm{ton}$ of water removed (Arlabosse et al., 2011). Adapting the operating conditions of paddle dryers in order to reach a sufficient DS content with regards to the subsequent application might result in more economically realistic solutions for SS valorization.

Literature on SS drying in paddle dryers is very scarce, and the state of the art in research does not allow predicting process performances. Indeed, predicting the DS content of sludge at the outlet of a paddle dryer would require calculating both the drying rate and the residence time distribution (RTD) of the sludge in given operating conditions. The first point has already been studied by several authors, and it is now accepted that the penetration theory can be used to describe accurately SS drying (Arlabosse and Chitu, 2007; Deng et al., 2009). However, RTD measurements remain a technical bottleneck for sludge processing and could bring valuable information for understanding sludge behavior in dryers.

RTD concept was first introduced by Danckwerts (1953) as a tool allowing characterization of fluid flows in reactors in a process. It relies on the measurement of a tracer concentration at the outlet of a reactor, the injection of this tracer being supposed not to disturb the flow. A lot of tracing techniques have been developed: they can be basically divided in two categories depending on whether they rely on online or offline analyses. The RTD concept can be employed for the characterization of any conservative flow (Gibilaro, 1979): for example, for the solid part of sludge flow in a dryer in our case. However, for solid flows, online tracing techniques such as magnetic field or radioactivity detection are complicated to set up. Optical techniques have also been tested, but most of the time they are operated offline (color analysis, fluorescence, and absorbance for example) since they might require pre-treatment of the samples (Gao et al., 2012). These optical techniques and other colored particle tracking techniques are not applicable with SS, since it is a very dark product. To date, only two studies focused on the determination of sludge RTD in paddle dryers: Tazaki et al. (2011) worked on an industrial scale installation in which they injected pulses of sludge enriched in 
nickel and manganese chloride. RTD was determined from the measurement of metal concentration in the samples (taken from different locations in the dryer) by flame atomic absorption spectrometry after mineralization. In a previous work, Charlou et al. (2013) worked on a pilot-scale continuous paddle dryer and validated a method of RTD determination by conductivity measurement. A pulse of sodium chloride dissolved in raw sludge was injected and processed sludge was sampled at the outlet of the pilot. Conductivity of the samples was then measured after leaching for $24 \mathrm{~h}$. The main drawbacks of these techniques are the time required for samples preparation in both cases, and for the conductivity technique the inability to make several measurements in a single experiment. In this paper, an original experimental methodology allowing measuring the residence time of SS in a pilot-scale continuous paddle dryer is presented. X-ray fluorescence allows detecting any mineral tracer and only requires drying and grinding of the samples. The repeatability of the technique and its equivalence to conductivity measurements are illustrated. Finally this methodology is applied to illustrate the influence of storage duration on SS flow during drying.

\section{Material and methods}

\subsection{Description of the installation}

Experiments were conducted on a continuous pilot-scale paddle dryer (Figure 1). A full description of the experimental set-up is available in a previous paper (Charlou et al., 2013). The main characteristics are summarized hereafter. The dryer is composed of a 1 meter long U-shaped jacketed trough housing a single rotating shaft equipped with 17 regularly spaced wedge-shaped paddles. Two additional blades, tilted at $45^{\circ}$, are placed at each end of the shaft to feed and extract the product more easily. An asynchronous motor rotates the shaft. A variable frequency drive permits a precise adjustment of the rotor's speed between 10 and $60 \mathrm{rpm}$. Scrapers are attached on the trough. Formed to interact with the paddles, the scrapers increase the shearing, aiding the handling of the sticky material and avoiding crust formation on the heated surfaces. Both the jacket and the shaft are electrically heated. Thermocouples positioned in the stator and in the rotor are used for temperature regulation. The trough is closed by a tight hood with three trap doors for sampling the sludge during or after the experiment. The hood and trough are insulated with a $5 \mathrm{~cm}$ thick rock wool to limit heat losses towards the outside. The whole set-up rests on a support which can be tilted of $\pm 5^{\circ}$. 


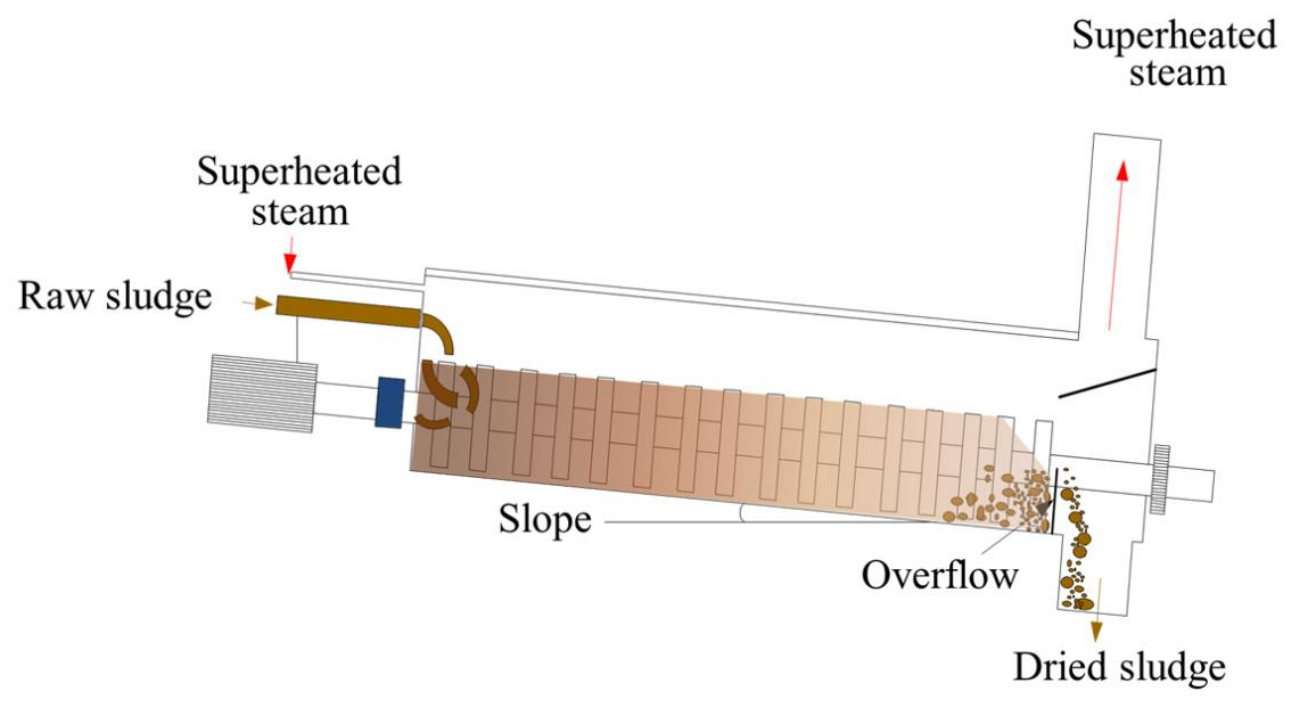

Figure 1: Scheme of the continuous paddle dryer

Sludge is fed from a 401 hopper by means of a Moineau pump whose flow rate can be accurately controlled. The sludge is fed above the shaft into one end of the trough and flows to the opposite end, where the dried material is discharged. The solids hold-up in the dryer is controlled through an adjustable overflow. For this study, the overflow was adjusted at its minimum position, corresponding to the height of the shaft. Superheated steam (1 atm, $160{ }^{\circ} \mathrm{C}$ ) is used as sweeping gas. The exhaust gases are pumped through a central exhaust port, treated with an activated carbon filter before being released outside. The installation is equipped with different sensors allowing recording temperatures and electrical power along the dryer, the torque applied by the motor as well as the mass of dried sludge at the outlet. This monitoring can help knowing whether a steady state operation has been reached. A posteriori, this data is used for establishing energy and mass balances on the drying process.

\subsection{Experimental procedure for RTD experiments}

\subsubsection{Sludge production}

The sludge used in this study comes from the Albi city WWTP (60 000 population equivalent). The effluent is treated via a biological-chemical phosphorus and nitrogen removal process. The activated sludge is flocculated with a cationic polymer, thickened and anaerobically digested for three weeks. The digested sludge is then flocculated and mechanically dewatered in centrifuges. After centrifugation, its dry matter content reaches 20 to $22 \%$. Sludge composition was analyzed according to standards EN 12880:2000; a typical composition is given in Table 1 (ultimate analysis considering organic matter only). 
Table 1: Typical sludge composition

\begin{tabular}{ccc}
\hline \multirow{2}{*}{$\begin{array}{c}\text { Proximate analysis } \\
\text { (\%wt. d.b.) }\end{array}$} & Mineral matter & 35 \\
\cline { 2 - 3 } & Organic matter & 65 \\
\cline { 2 - 3 } & $\mathrm{C}$ & 56.9 \\
\cline { 2 - 3 } Ultimate analysis & $\mathrm{H}$ & 8.2 \\
\cline { 2 - 3 }$(\%$ wt. OM) & $O^{*}$ & 24.3 \\
\cline { 2 - 3 } & $\mathrm{N}$ & 8.8 \\
\hline
\end{tabular}

* By difference

For this study, sludge was sampled over a period of two months during which no change in the operating conditions of the WWTP was reported. Before each experiment, the sludge was stored in air-tight containers in a cold room at $+4{ }^{\circ} \mathrm{C}$ for at least two days. All the experiments were performed within two weeks following the sampling.

\subsubsection{Steady state operation determination}

Reaching a steady state operation during SS drying experiments is not straightforward: the sludge outlet flow rate alone is not reliable, since sludge water content can vary during transitory periods. Moreover, water content measurement requires several hours (usually $24 \mathrm{~h}$ at $105{ }^{\circ} \mathrm{C}$ according to standards). This issue was dealt with by monitoring continuously the torque applied by the stirrer along with the mass at the outlet. Figure 2 illustrates the relationship between torque and partially dried sludge flow rate at the outlet of the dryer. The average water content of SS at the outlet of the dryer was $0.51 \pm 0.1 \mathrm{~kg} / \mathrm{kg}$ and flow rate data is averaged on 30 min periods. After a period of stability, an increase in torque value is accompanied by a decrease in average flow rate and conversely. This indicates that an accumulation of sludge occurred, followed by a partial purge of the material in the reactor. It is difficult to anticipate such a behavior, which is probably linked to the stickiness of the sludge during drying (Kudra, 2003).

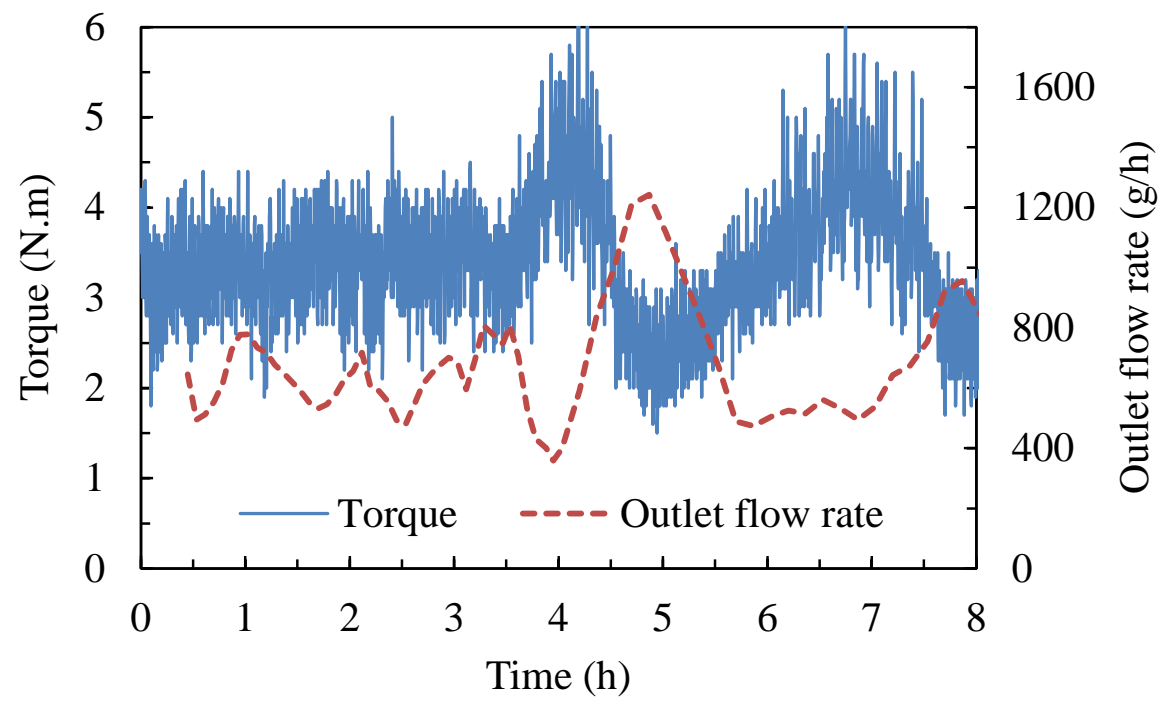

Figure 2: Evolution of outlet flow rate and torque during drying experiments 


\section{$\underline{2.2 .3 \text { Tracer preparation and injection }}$}

Tracers were prepared by mixing raw sludge with different minerals. These minerals were selected according to three criteria: their concentration in the raw sludge, their solubility in water and their sensitivity to XRF analysis. Table 2 provides a screening analysis of 24 elements present in a dry sludge sample from Albi WWTP analyzed in an energy dispersion $\mathrm{X}$-ray fluorescence spectrometer (Epsilon $3 \mathrm{XL}$, PANalytical). This equipment allows semiquantitative elemental analyses of finely ground solids (for elements heavier than oxygen). For the analysis, the $10 \mathrm{~mm}$ thick sample was disposed over a Mylar film $(6.3 \mu \mathrm{m})$ in a 28 $\mathrm{mm}$ diameter sample holder. As expected, SS contains fertilizing nutrients like phosphorus, potassium, magnesium, calcium and sulfur. The high iron concentration results from the use of ferric chloride both for coagulation and phosphorus removal. Other elements are present in very low concentrations.

Table 2: Semi-quantitative XRF analysis of the raw sludge

\begin{tabular}{cc|cc|cc}
\hline \multicolumn{6}{c}{ Element concentrations $(w t \%)$} \\
\hline $\mathrm{Fe}$ & 15.71 & $\mathrm{Ti}$ & 0.77 & $\mathrm{Sr}$ & 0.07 \\
\hline $\mathrm{Ca}$ & 8.98 & $\mathrm{Zn}$ & 0.55 & $\mathrm{Br}$ & 0.04 \\
\hline $\mathrm{Si}$ & 7.67 & $\mathrm{Cu}$ & 0.27 & $\mathrm{I}$ & 0.04 \\
\hline $\mathrm{P}$ & 7.40 & $\mathrm{Cl}$ & 0.25 & $\mathrm{Zr}$ & 0.03 \\
\hline $\mathrm{S}$ & 2.58 & $\mathrm{~Pb}$ & 0.23 & $\mathrm{Cr}$ & 0.03 \\
\hline $\mathrm{Mg}$ & 2.55 & $\mathrm{Ba}$ & 0.11 & $\mathrm{Ni}$ & 0.01 \\
\hline $\mathrm{Al}$ & 1.23 & $\mathrm{Mn}$ & 0.08 & $\mathrm{Rb}$ & 0.01 \\
\hline $\mathrm{K}$ & 1.02 & $\mathrm{Sn}$ & 0.08 & $\mathrm{Mo}$ & 0.01 \\
\hline
\end{tabular}

In a previous work, RTD were characterized by conductivity titration, using sodium chloride as a tracer (Charlou et al., 2013). Chloride is again selected in this study so as to compare the sensitivity of the two detection methods (conductivity versus XRF analysis). But sodium chloride is soluble to some extent in water. Tracers with different water solubility were used so as to characterize both the RTD of the dry matter and the sludge. Four other elements were identified as suitable tracers: iodide and bromide, available as potassium salts, and titanium and zirconium, available as oxides. Table 3 gives the solubility of these tracers in pure water at ambient temperature. 
Table 3: Tracer solubility in pure water

\begin{tabular}{cccc}
\hline Element & Tracer & Purity (\% wt.) & Solubility in water at $20^{\circ} \mathrm{C}(\%$ wt. $)$ \\
\hline $\mathrm{Zr}$ & $\mathrm{ZrO}_{2}$ & 99 & insoluble \\
\hline $\mathrm{Ti}$ & $\mathrm{TiO}_{2}$ & 99 & insoluble \\
\hline $\mathrm{Cl}$ & $\mathrm{NaCl}$ & 99.5 & 35.9 \\
\hline $\mathrm{Br}$ & $\mathrm{KBr}$ & 99.5 & 65.3 \\
\hline $\mathrm{I}$ & $\mathrm{KI}$ & 99 & 144 \\
\hline
\end{tabular}

For the RTD experiments, the sludge tracer is inserted in a flexible tube. Once the stationary state is reached, this flexible tube is placed between the pump and the dryer inlet. The injection is considered to be a Dirac pulse function, even though the time required for the injection of the tracer was about $2 \%$ of the residence time measured. In the following, around $10 \mathrm{~g}$ of tracer was added to $90 \mathrm{~g}$ of raw sludge to prepare a tracing pulse of sludge, except for sodium chloride. The sensitivity of the conductivity measurements being lower, typically about $50 \mathrm{~g}$ of sodium chloride were mixed with $50 \mathrm{~g}$ of sludge. Dry solid (DS) contents of the tracing sludge are reported in Table 4. Addition of potassium salts or metal oxides does not change much the water content. Consequently, it can be expected that the hydrodynamics will not be disturbed by the pulse injection of tracer.

Table 4: DS contents of sludge mixed with tracer

\begin{tabular}{ccc}
\hline Tracer & $\mathrm{NaCl}$ & Potassium salts and metal oxides \\
\hline Mass ratio of sludge/tracer & $50 / 50$ & $90 / 10$ \\
\hline DS content $(\%)$ & 60 & 28 \\
\hline
\end{tabular}

\subsubsection{Sludge sampling and XRF analysis}

After injecting a tracer, all the partially dried sludge at the outlet of the dryer is collected every 5 or 10 minutes. This sampling lasts for at least 6 hours. In this study, X-Ray fluorescence is retained as main detection method since it allows several successive injections of tracers during a single experiment. Nevertheless to establish continuity with former work, a comparison with conductivity measurements is proposed. For both techniques, each sample is first dried at $105{ }^{\circ} \mathrm{C}$ for $24 \mathrm{~h}$, ground coarsely and then prepared for further analysis. For conductivity measurement, the principle is to leach the whole sample during $24 \mathrm{~h}$ before measuring the conductivity of the leachate (Charlou et al., 2013). For XRF analysis, the sludge is quarted until a representative sample of $7 \mathrm{~g}$ can be isolated.

Sludge samples with different tracer concentrations were prepared for XRF calibration. The raw intensity for each tracer was then recorded and baseline value was subtracted. Figure 3 represents the net intensity (in counts per second for each element) obtained for different tracer concentrations (expressed as $\mathrm{mg}$ of tracer per $\mathrm{g}$ of dried sludge) in the case of bromide and iodide potassium salts. In the range tested here, which corresponds to the expected 
concentration at the dryer outlet, the response is linear with the tracer concentration in the dried sludge.

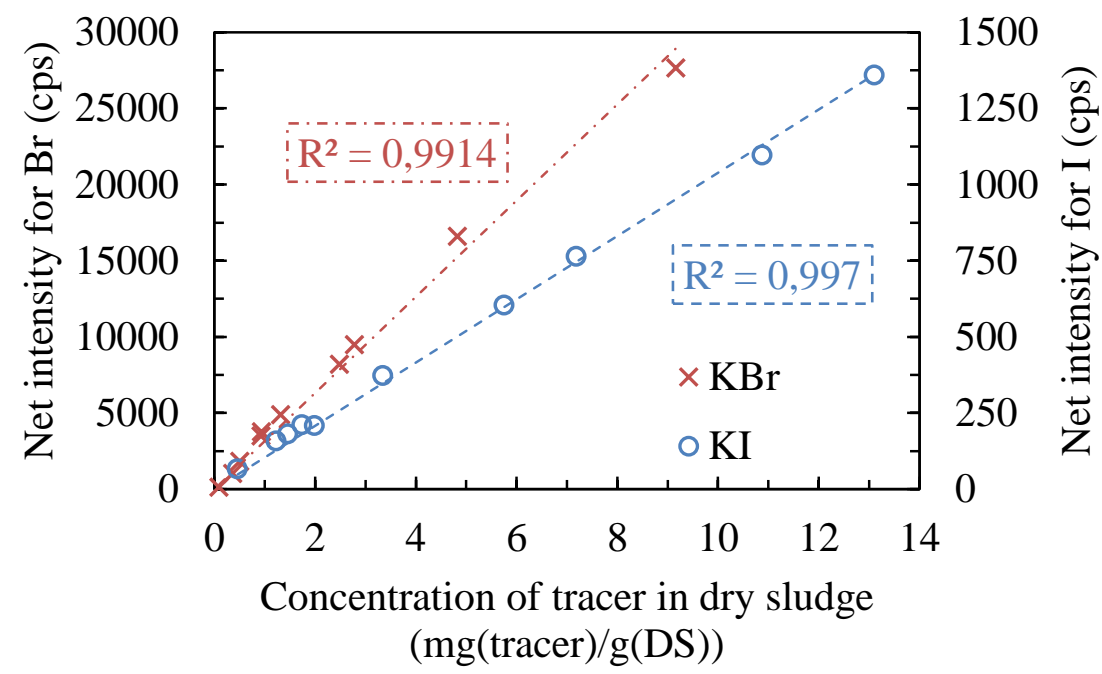

Figure 3: XRF calibration curves for sludge and salts mixtures

The sensitivity of the measurement (expressed in counts per second per $g$ of tracer per $g$ of dried sludge) is plotted in Figure 4 for each potential tracer. Zirconium and bromide are by far the most sensitive elements. The sensitivities of titanium and iodine are appreciably equivalent and lower than that of chloride. Nevertheless, even for these tracers, very low concentrations can be determined by XRF analysis.

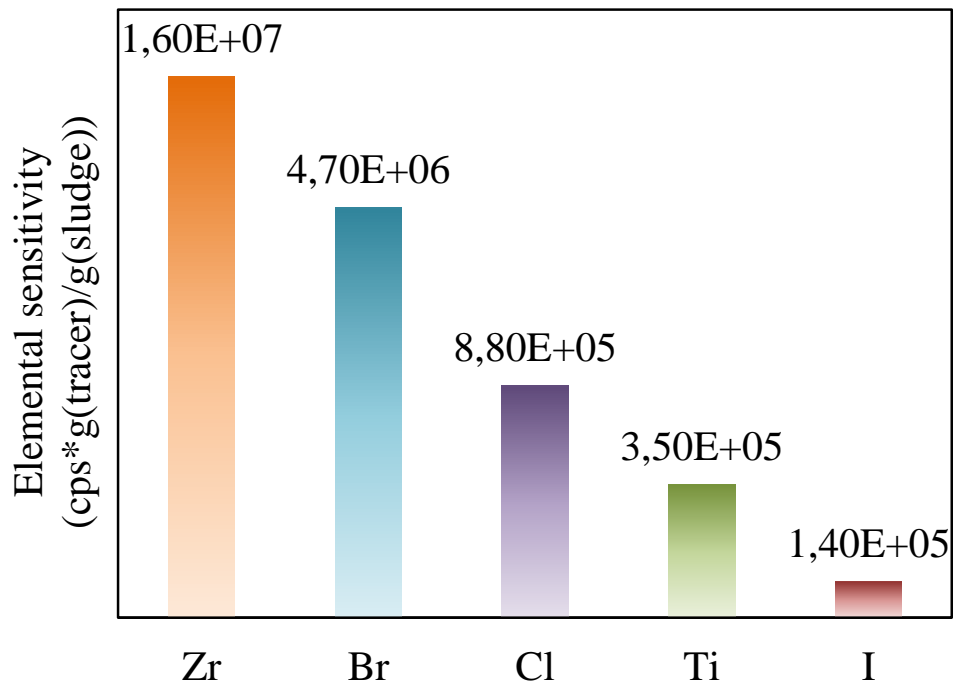

Figure 4: Sensitivity to XRF analysis of the different tracers used

\subsection{Analysis of RTD experiments}

RTD functions $\mathrm{E}(\mathrm{t})$ and $\mathrm{F}(\mathrm{t})$ are calculated by integrating the concentrations obtained at each sampling time according to Equations 1 and 2, where $t_{i}$ is the time at the $\mathrm{i}^{\text {th }}$ sampling, $n$ is the 
total number of samples and $\Delta t_{i}$ represents the time between the $\mathrm{i}^{\text {th }}$ sampling and the previous one.

$$
\begin{aligned}
& E\left(t_{i}\right)=C\left(t_{i}\right) / \sum_{j=2}^{n} C\left(t_{j}\right) \Delta t_{j} \\
& F\left(t_{i}\right)=\sum_{j=2}^{i} C\left(t_{j}\right) \Delta t_{j} / \sum_{j=2}^{n} C\left(t_{j}\right) \Delta t_{j}
\end{aligned}
$$

Equation 1

Equation 2

The mean residence time $\bar{t}$ and the variance of the RTD $\sigma^{2}$ are deduced from these functions according to Equations 3 and 4.

$$
\begin{aligned}
& \bar{t}=\sum_{i=2}^{n} t_{i} E\left(t_{i}\right) \Delta t_{i} \\
& \sigma^{2}=\sum_{i=2}^{n}\left(t_{i}-\bar{t}\right)^{2} E\left(t_{i}\right) \Delta t_{i}
\end{aligned}
$$

Equation 3

Equation 4

The dimensionless variance $\sigma_{D}^{2}$ is then obtained with Equation 5. $\sigma_{D}^{2}$ is a measure of the deviation from two extreme cases : plug flow $\left(\sigma_{D}^{2}=0\right)$ and continuous stirred tank $\left(\sigma_{D}^{2}=1\right)$ reactors.

$$
\sigma_{D}^{2}=\sigma^{2} / \bar{t}^{2}
$$

Equation 5

The geometric residence time $\tau$ is defined as the ratio of flow rate to hold-up of a given reactor: this parameter can be compared to $\bar{t}$ in order to diagnose the presence of by-passes or dead volumes. The applicability of this approach to sludge drying is worth discussing: classically, RTD experiments are limited to single phase, incompressible flows. Dewatered sludge, as used in this study, is composed of about $80 \%$ of water. However, it does not behave as a liquid or as a solid phase, but evolves from a pasty material to particulate solids as a result of water evaporation: its flow rate is consequently not conservative in the reactor. This issue is avoided by considering only the flow rate $\dot{m}_{D S}$ and hold up $H_{D S}$ of dry solids in our dryer. The geometric residence time is thus given by Equation 6 .

$$
\tau=H_{D S} / \dot{m}_{D S}
$$

Equation 6

At the end of each RTD experiment, sludge feed and stirring are stopped simultaneously: the remaining sludge is recovered after cooling, further dried in an oven and finally weighted to determine $H_{D S}$. The DS flow rate is deduced from the mean sludge flow rate during the experiments and its initial water content.

\section{$\underline{\text { 3. Results and discussion }}$}

\section{$\underline{\text { 3.1 Multiple RTD analysis by XRF }}$}

\section{$\underline{3.1 .1 \text { Repeatability and steady state operation }}$}


In a previous paper, a satisfactory repeatability of RTD measurements with the conductivity method was obtained on several experiments performed in the same operating conditions (Charlou et al., 2013). With the new methodology presented here, several RTD measurements in a single experiment were performed by injecting several tracers at different times during the experiment and analyzing them simultaneously by XRF. The operating conditions used for this experiment are summarized in Table 5. The inlet and outlet water content of SS were respectively $3.78 \pm 0.03 \mathrm{~kg} / \mathrm{kg}$ and $1.02 \pm 0.09 \mathrm{~kg} / \mathrm{kg}$. Figure 5 represents the resulting RTD obtained for three tracers injected successively (first $\mathrm{KI}$, then $\mathrm{ZrO}_{2}$ after $1.25 \mathrm{~h}$ and $\mathrm{NaCl}$ after $1.7 \mathrm{~h}$ ). The RTDs obtained after analysis of the dried samples have similar shapes during an apparently steady state operation.

Table 5: Operating conditions

\begin{tabular}{|c|c|c|}
\hline DS flc & ow rate & $510 \mathrm{~g} / \mathrm{h}$ \\
\hline Dryer & slope & $3^{\circ}$ \\
\hline Dryer wall & temperature & $160^{\circ} \mathrm{C}$ \\
\hline Stirrer & speed & $28 \mathrm{rpm}$ \\
\hline \multirow{3}{*}{$\begin{array}{c}\text { Superheated } \\
\text { steam }\end{array}$} & Temperature & $160^{\circ} \mathrm{C}$ \\
\hline & Flow rate & $1.1 \mathrm{~kg} / \mathrm{h}$ \\
\hline & Pressure & $1 \mathrm{~atm}$ \\
\hline
\end{tabular}

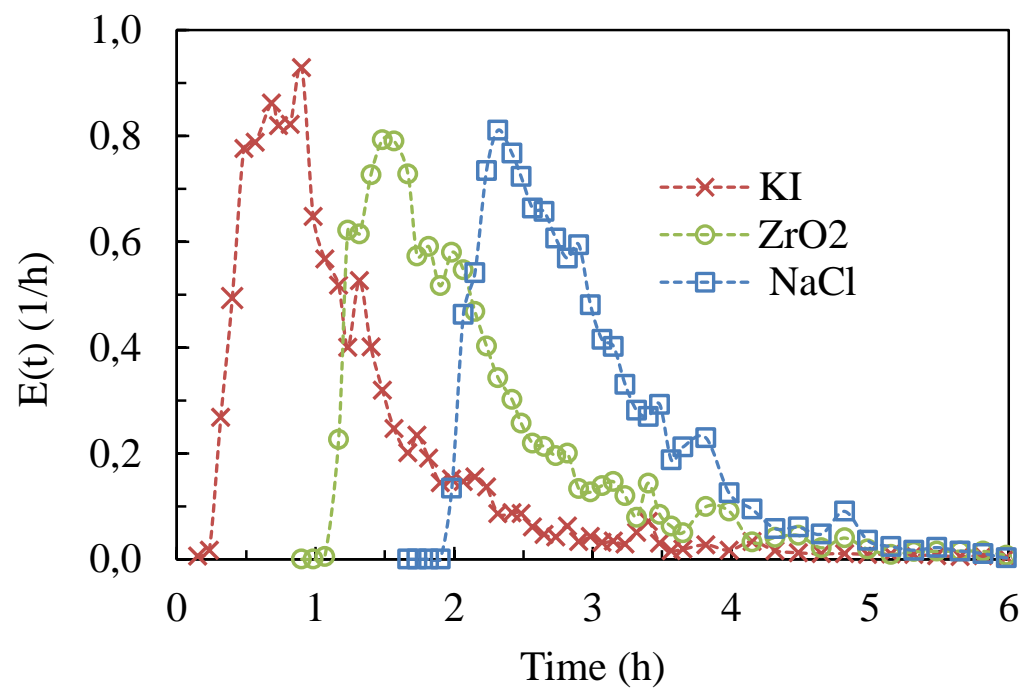

Figure 5: RTDs obtained for three successive injections of different tracers during a single experiment

The corresponding cumulative RTDs are illustrated on Figure 6, where they are plotted against the time elapsed since the tracer injection. The obvious repeatability of the tracing technique, which appears on Figure 6 , is assessed by the values of $\bar{t}$ calculated in Table 6 . For all cases $(\bar{t}-\tau) / \tau<5 \%$ so there are no significant bypasses or dead volumes in the dryer. These mean residence time values are reliable because sampling times were at least 4 times that of mean residence time (Martin, 2000). $\sigma_{D}^{2}$ values indicate that the system stage is intermediate between plug flow and perfect mixing, because of the paddles acting locally as mixers. The value of $\sigma_{D}^{2}$ for the last injection $(\mathrm{NaCl})$ is lower than the previous ones: this 
might be due to the fact that the sampling duration for this last RTD was lower than the previous. Variance calculation is indeed sensitive to the shape of the trailing part of the RTD.

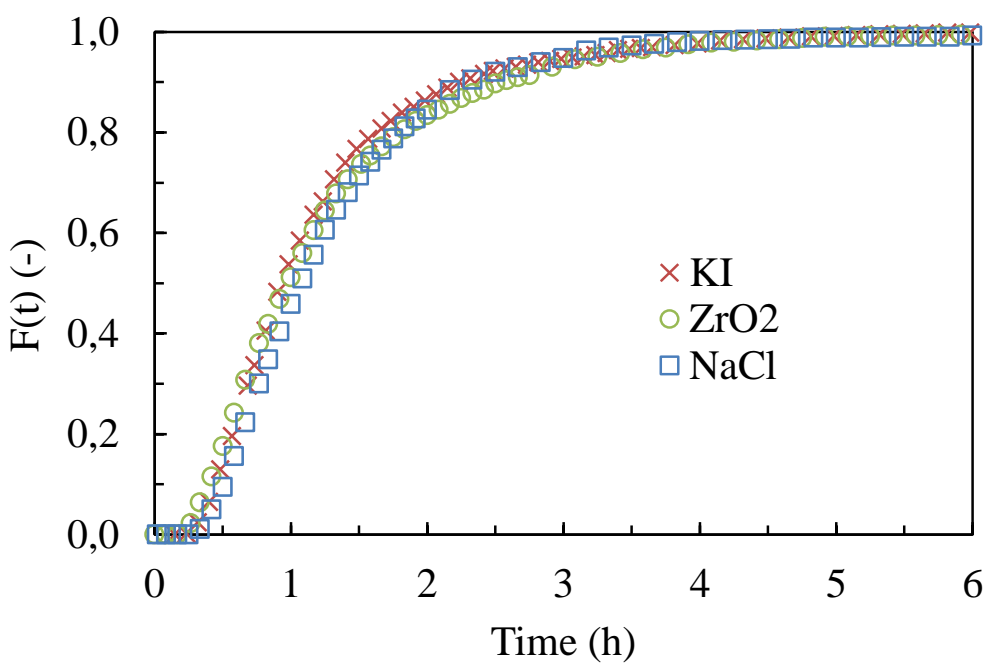

Figure 6: Cumulative RTD obtained for three successive injections of different tracers during a single experiment

This repeatability of RTD measurements is to be related to the steady state operation of the dryer. As previously explained, torque and outlet sludge flow rate evolutions are representative of the flow stability inside the dryer. For this experiment, these data are illustrated on Figure 7: both the torque applied to the stirrer and the flow rate of DS in sludge outlet indicate a stationary operation. However, since the outlet of sludge is relatively irregular between two samplings, the calculated flow rate is also scattered. By considering the cumulated sludge mass, as illustrated in Figure 8, one can see that the evolution of sludge at the outlet as well as that of DS both follow a linear trend, which is another indication of a stationary regime and shows that the DS content of the sludge at the outlet is constant. Thanks to the good repeatability of the RTD measurements, it was verified that the double criterion of torque and outlet flow rate stability is sufficient to characterize a steady state operation in our paddle dryer.

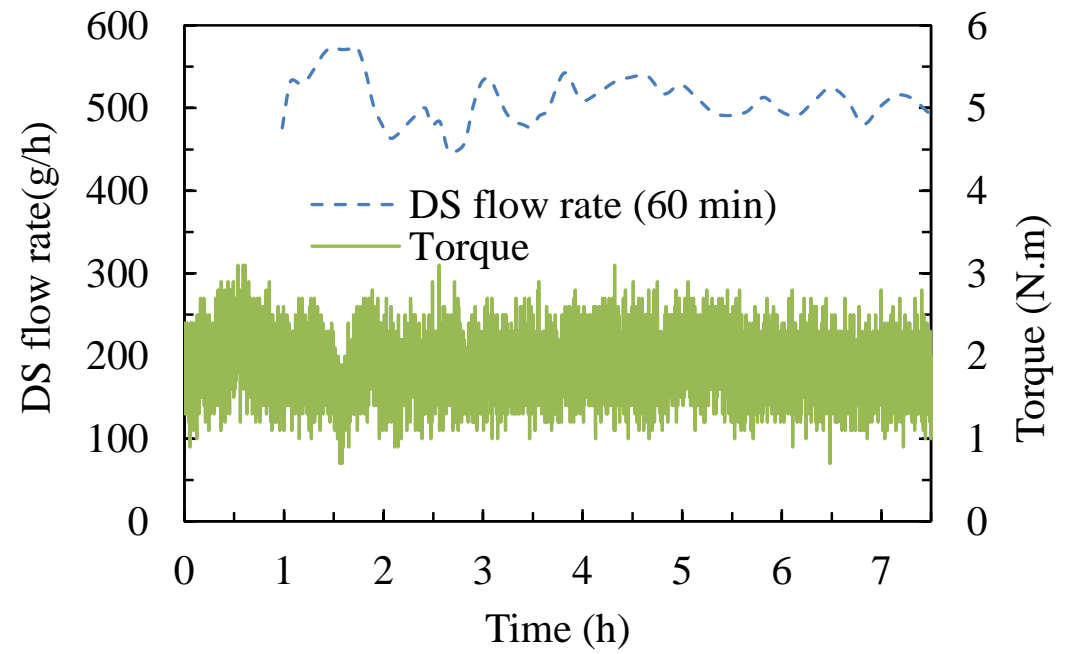

Figure 7: Evolution of torque and outlet DS flow rate (averaged over $60 \mathrm{~min}$ ) during the same period as in Figure 5 


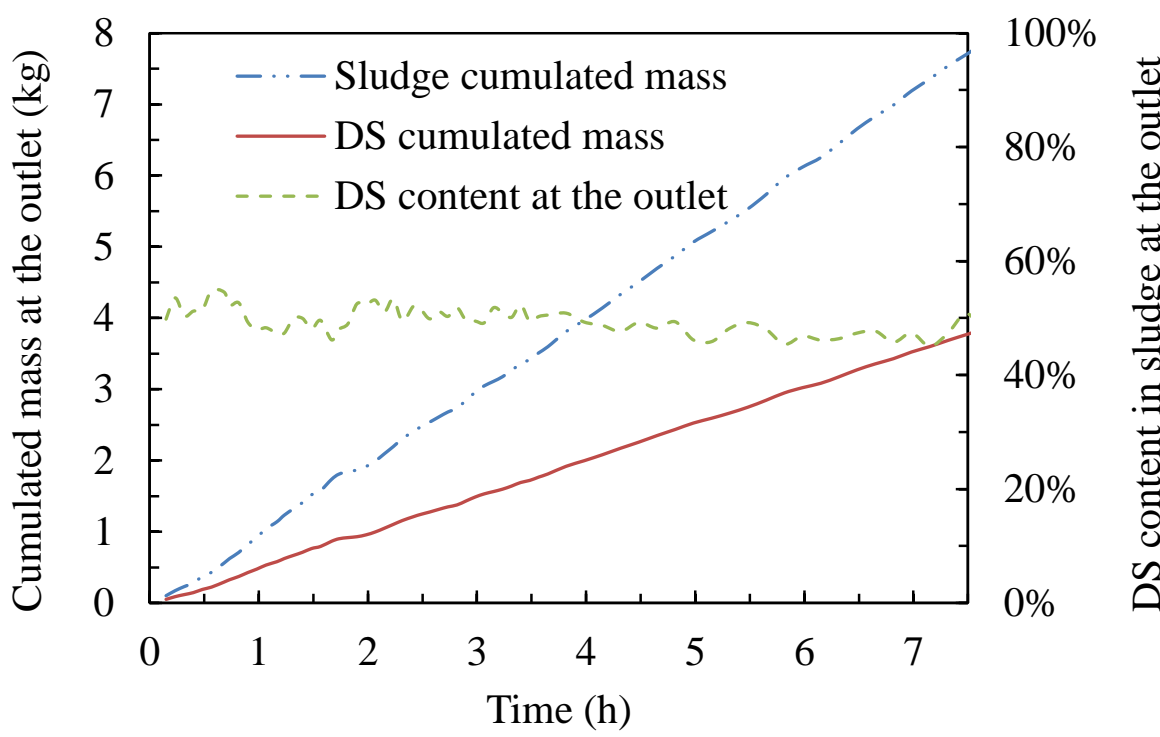

Figure 8: Evolution of sludge mass at the outlet of the dryer, corresponding DS mass and DS content during the same period as in Figure 5

Another interesting observation is that similar results are obtained with all the tracers, even though the tracing sludge impulse made with sodium chloride presents a much higher DS content than the others (Table 4). This indicates that varying DS contents in sludge impulses do not influence significantly sludge flow in the dryer. It is then possible to carry out multiple tracer injections, by incorporating several tracers in the same sludge impulse.

\subsubsection{Discussion on tracer solubility}

For the RTD experiments presented earlier, tracers of varying solubility in water were used: zirconia oxide is totally insoluble while sodium chloride is soluble to some extent and potassium iodide has the highest solubility. Assuming that the water in SS behaves as pure water, Table 7 gives the approximate amount of tracer that is supposed to be in liquid phase when prepared according to the proportion given earlier (Table 4). This is an estimation of the part that is actually dissolved in the free water comprised in SS before the injection. As soon as the tracer is injected, it is diluted and heated up so it is probable that a greater part of the sodium chloride was actually dissolved at the beginning of the experiments.

Table 7: Amount of tracer dissolved in the liquid phase of SS

\begin{tabular}{cc}
\hline Tracer & Amount of tracer dissolved \\
\hline $\mathrm{ZrO}_{2}$ & $0 \%$ \\
\hline $\mathrm{NaCl}$ & $36 \%$ \\
\hline $\mathrm{KI}$ & $100 \%$ \\
\hline
\end{tabular}

Nevertheless, all the RTD are superimposed (Table 6, Figure 6), whatever the tracer solubility. This result means that dewatered sludge behaves as a single phase in terms of flow, even at DS contents as low as $20 \%$. In other words, it is possible to consider only the DS flow for sludge flow characterization in a paddle dryer. 


\subsection{Comparison of XRF and conductivity techniques}

An experiment with a single injection of $\mathrm{NaCl}$ tracer was realized, in operating conditions identical to the previous one except for the stirring speed set at $21 \mathrm{rpm}$. Inlet and outlet water content of SS were respectively $3.55 \pm 0.03 \mathrm{~kg} / \mathrm{kg}$ and $0.67 \pm 0.26 \mathrm{~kg} / \mathrm{kg}$. Figure 9 compares the RTD obtained with the two analysis techniques (conductivity and XRF). The calculated mean residence times and variances are reported in Table 8. Both RTD curves have a similar shape, resulting in very close values of $\bar{t}$, with a relative difference of $6.5 \%$. However, the tail of the curve for the conductivity analysis presents slightly higher values than for the XRF technique. If this is of minor importance on the previous calculation, the values of variance differ much more: it is almost $25 \%$ higher for the conductivity method than for XRF technique.

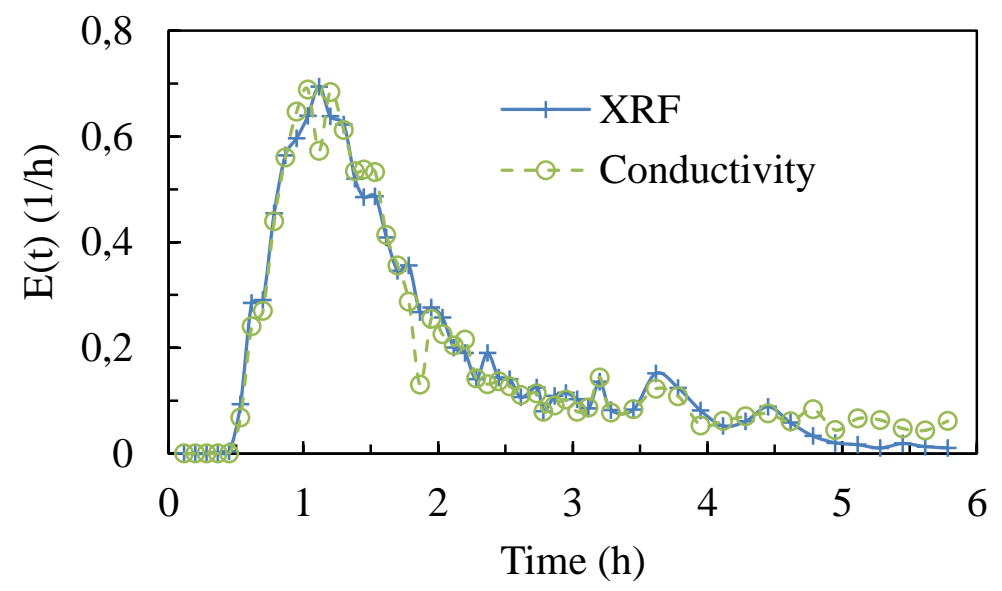

Figure 9: Comparison of RTD obtained with the two analytical techniques for a same experiment

This difference may be explained by the low sensibility of the conductivity measurement, where the ratio between the maximum intensity and the baseline is around 4, while it is about 15 for XRF analysis with chloride. The lower values of $E(t)$ are thus very sensitive to experimental error measurements in the conductivity technique. In spite of these slight differences, the equivalence of the two methods can be validated. However, the higher sensitivity of the XRF technique makes it more suitable for these experiments since there is no need to mix as much tracer as for the conductivity technique, which decreases the DS content difference between tracer and bulk sludge flow (Table 4).

\section{$\underline{3.3 \text { Influence of sludge storage duration on sludge flow and dryer efficiency }}$}

This new methodology was applied in order to study the influence of storage time on sludge behavior during drying in our installation. After sampling at the WWTP, a first batch of sludge was kept $24 \mathrm{~h}$ at $4{ }^{\circ} \mathrm{C}$ in air-tight containers before a drying experiment. A second batch was kept $48 \mathrm{~h}$ at $4{ }^{\circ} \mathrm{C}$ before the next experiment. The operating conditions were a steam and wall temperature of $160{ }^{\circ} \mathrm{C}$, a DS flow rate of $380 \mathrm{~g} / \mathrm{h}$, a dryer slope of $3^{\circ}$ and a stirring speed set at $28 \mathrm{rpm}$. Table 9 shows the drying efficiencies for these experiments in terms of average drying rate over the whole reactor: as already observed in a batch lab-scale indirect agitated dryer (J. H. Ferrasse, 2002), SS seems to have a lower drying rate when 
stored at $4{ }^{\circ} \mathrm{C}$ for only $24 \mathrm{~h}$ after sampling at the WWTP than when stored for $48 \mathrm{~h}$. When stored at a higher temperature of $12{ }^{\circ} \mathrm{C}$, SS appears to have a different behavior, with decreasing drying rates with storage duration (Fraikin et al., 2011). However, in another study on convective SS drying this behavior was not reported, and no significant change in drying rate was noticed until two weeks of storage at $25^{\circ} \mathrm{C}$ under slow stirring (Pambou Y.B. et al., 2013).

Table 9: Influence of storage duration on dryer efficiency

\begin{tabular}{cccc}
\hline $\begin{array}{c}\text { Storage } \\
\text { duration } \\
(\mathrm{h})\end{array}$ & $\begin{array}{c}\text { Inlet moisture } \\
\text { content } \\
\left(\mathrm{kg}_{\mathrm{w}} / \mathrm{kg}_{\mathrm{DS}}\right)\end{array}$ & $\begin{array}{c}\text { Outlet moisture } \\
\text { content } \\
\left(\mathrm{kg}_{\mathrm{w}} / \mathrm{kg}_{\mathrm{DS}}\right)\end{array}$ & $\begin{array}{c}\text { Average } \\
\text { drying rate } \\
\left(\mathrm{kg}_{\mathrm{w}} / \mathrm{h}\right)\end{array}$ \\
\hline $24 \mathrm{~h}$ & 3.28 & $0.54 \pm 0.08$ & 1.02 \\
\hline $48 \mathrm{~h}$ & 3.29 & $0.15 \pm 0.05$ & 1.25 \\
\hline
\end{tabular}

In order to get more insight into SS behavior, three tracer injections were carried out with potassium iodide, titanium dioxide and potassium bromide for each experiment. As can be seen in Table 10, the three RTDs were repeatable, with low standard errors on $\bar{t}$ and $\sigma^{2}$ values in both cases. These parameters show very large differences between the two experiments with a much sharper shape and lower peak time for the RTD of SS stored $24 \mathrm{~h}$, as illustrated in Figure 10 for KI tracer for both differential and cumulative RTDs. As a result, it appears that SS flow is much closer to a plug flow when stored only $24 \mathrm{~h}$, with a $\sigma_{D}^{2}$ value of 0.40 against 0.23 for SS stored for $48 \mathrm{~h}$.

Table 10: Influence of storage duration on mean residence time and variance

\begin{tabular}{ccccc}
\hline $\begin{array}{c}\text { Storage } \\
\text { duration }\end{array}$ & Tracer & $\begin{array}{c}\overline{\boldsymbol{t}} \\
(\mathrm{h})\end{array}$ & $\begin{array}{c}\boldsymbol{\sigma}^{2} \\
\left(\mathrm{~h}^{2}\right)\end{array}$ & $\begin{array}{c}\boldsymbol{\sigma}_{\boldsymbol{D}}^{\mathbf{2}} \\
(-)\end{array}$ \\
\hline \multirow{3}{*}{$24 \mathrm{~h}$} & $\mathrm{KI}$ & 1.68 & 1.12 & 0.4 \\
& $\mathrm{KBr}$ & 1.56 & 1.01 & 0.41 \\
& $\mathrm{TiO}_{2}$ & 1.64 & 1.07 & 0.4 \\
\cline { 2 - 5 } & Mean & $1.62 \pm 0.06$ & $1.07 \pm 0.06$ & $0.40 \pm 0.01$ \\
\hline \multirow{4}{*}{$48 \mathrm{~h}$} & $\mathrm{KI}$ & 2.90 & 1.89 & 0.22 \\
& $\mathrm{KBr}$ & 2.90 & 2.05 & 0.24 \\
& $\mathrm{NaCl}$ & 2.82 & 1.80 & 0.23 \\
\cline { 2 - 5 } & Mean & $2.87 \pm 0.05$ & $1.91 \pm 0.13$ & $0.23 \pm 0.01$ \\
\hline
\end{tabular}

These observations suggest that drying efficiency is not sufficient to draw conclusions on the influence of storage duration on SS drying behavior in a continuous dryer. Indeed, considering that there are no dead volumes in the reactor, according to Equation 6 the solids hold-up in these experiments was almost twice as much for SS stored $48 \mathrm{~h}$ than for that stored $24 \mathrm{~h}$. From this point of view, the total contact area would also have been different between these experiments, and the drying fluxes calculated according to this area could show a different trend than the drying rates in Table 9. However, an accurate estimation of these 
parameters is beyond the scope of the present paper and would require more experimental data than was available for these experiments.

\section{$\underline{4 \text { - Conclusions }}$}

An original methodology for experimental RTD measurements was developed, based on XRF analysis. This technique allows working with a large range of mineral tracers, and realizing multiple tracer injections in a single experiment. The repeatability of tracer detection was assessed and its equivalence to RTD measurement by conductivity was verified. By injecting tracers with different water solubility, it was shown that the RTD of wet sludge is the same than that of the dry solids, so sludge can be considered as a water-saturated solid phase. A practical consequence is that SS flow can be described by knowing the dry solids hold up and flow rate only. This methodology was applied to the characterization of RTD for SS stored for 24 and $48 \mathrm{~h}$ in a cold room. It was shown that storage duration influences strongly RTD; however, further study is necessary in order to understand the mechanisms implied in this phenomenon. The present methodology will be applied to study the influence of operating parameters on sludge drying in a paddle dryer, such as stirring speed, or to obtain experimental data for numerical modeling validation. It is also applicable to any kind of reactor processing pasty products.

\section{$\underline{\text { References }}$}

Arlabosse, P., Chitu, T., 2007. Identification of the Limiting Mechanism in Contact Drying of Agitated Sewage Sludge. Dry. Technol. 25, 557-567. doi:10.1080/07373930701226955

Arlabosse, P., Ferrasse, J.-H., Lecomte, D., Crine, M., Dumont, Y., Léonard, A., 2011. Efficient Sludge Thermal Processing: From Drying to Thermal Valorization, in: Tsotsas, E., Mujumdar, A.S. (Eds.), Modern Drying Technology. Wiley-VCH Verlag GmbH \& Co. KGaA, pp. 295-329.

Charlou, C., Sauceau, M., Arlabosse, P., 2013. Characterisation of Residence Time Distribution in a Continuous Paddle Dryer. J. Residuals Sci. Technol. 10, 117-125.

Chen, G., Lock Yue, P., Mujumdar, A.S., 2002. Sludge Dewatering and Drying. Dry. Technol. 20, 883-916. doi:10.1081/DRT-120003768

Danckwerts, P.V., 1953. Continuous flow systems: Distribution of residence times. Chem. Eng. Sci. 2, 1-13. doi:10.1016/0009-2509(53)80001-1

Deng, W.-Y., Yan, J.-H., Li, X.-D., Wang, F., Lu, S.-Y., Chi, Y., Cen, K.-F., 2009. Measurement and simulation of the contact drying of sewage sludge in a Nara-type paddle dryer. Chem. Eng. Sci. 64, 5117 - 5124. doi:http://dx.doi.org/10.1016/j.ces.2009.08.015

Ferrasse, J. H., Arlabosse, P., 2002. Heat, momentum and mass transfer measuremnts in indirect agitated sludge dryer. Dry. Technol. 20, 749-769. doi:10.1081/DRT-120003755

Ferrasse, J.-H., Seyssiecq, I., Roche, N., 2003. Thermal Gasification: A Feasible Solution for Sewage Sludge Valorisation? Chem. Eng. Technol. 26, 941-945. doi:10.1002/ceat.200301813 
Fraikin, L., Salmon, T., Herbreteau, B., Levasseur, J.-P., Nicol, F., Crine, M., Léonard, A., 2011. Impact of Storage Duration on the Gaseous Emissions during Convective Drying of Urban Residual Sludges. Chem. Eng. Technol. 34, 1172-1176. doi:10.1002/ceat.201100071

Fytili, D., Zabaniotou, A., 2008. Utilization of sewage sludge in EU application of old and new methods--A review. Renew. Sustain. Energy Rev. 12, 116-140.

Gao, Y., Muzzio, F.J., Ierapetritou, M.G., 2012. A review of the Residence Time Distribution (RTD) applications in solid unit operations. Powder Technol. 228, 416-423. doi:10.1016/j.powtec.2012.05.060

Gendebien, A., 2010. Environmental, economic and social impacts of the use of sewage sludge on land, Part 3. European Commission.

Gibilaro, L.G., 1979. Residence time distributions in regions of continuous flow systems. Chem. Eng. Sci. 34, 697-702. doi:10.1016/0009-2509(79)85116-7

Kudra, T., 2003. Sticky Region in Drying: Definition and Identification. Dry. Technol. 21, 1457-1469. doi:10.1081/DRT-120024678

Manara, P., Zabaniotou, A., 2012. Towards sewage sludge based biofuels via thermochemical conversion - A review. Renew. Sustain. Energy Rev. 16, 2566-2582. doi:10.1016/j.rser.2012.01.074

Martin, A.D., 2000. Interpretation of residence time distribution data. Chem. Eng. Sci. 55, 5907-5917. doi:10.1016/S0009-2509(00)00108-1

Mininni, G., Di Bartolo Zuccarello, R., Lotito, V., Spinosa, L., Di Pinto, A.C., 1997. A design model of sewage sludge incineration plants with energy recovery. Water Sci. Technol. 36, 211-218. doi:10.1016/S0273-1223(97)00685-9

Pambou Y.B., Fraikin L., Salmon T., Crine M., Léonard A., 2013. Impact of sludge storage duration on its dewatering and drying ability. Presented at the Eurodrying 2013, Paris.

Tazaki, M., Tsuno, H., Takaoka, M., Shimizu, K., 2011. Modeling of Sludge Behavior in a Steam Dryer. Dry. Technol. 29, 1748-1757. doi:10.1080/07373937.2011.602811 